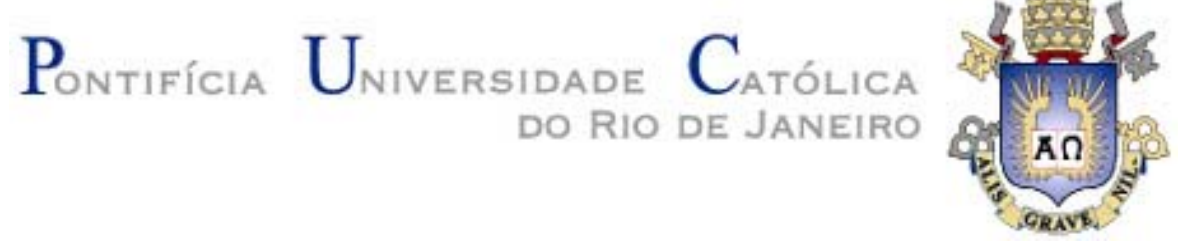

Ricardo do Nascimento Bacellar

\begin{abstract}
Casamento de Princesa: um estudo exploratório sobre o significado de consumo para noivas no Rio de Janeiro
\end{abstract}

Dissertação de Mestrado

Dissertação apresentada ao Programa de Pósgraduação em Administração de Empresas da PUCRio como requisito parcial para obtenção do título de Mestre em Administração de Empresas

Orientador: Prof. Luis Fernando Hor-Meyll Alvares

Rio de Janeiro

Julho de 2012 
Ricardo do Nascimento Bacellar

\title{
Casamento de Princesa: Um estudo exploratório sobre o significado de consumo para noivas no Rio de Janeiro
}

\begin{abstract}
Dissertação apresentada como requisito parcial para obtenção do grau de Mestre pelo Programa de Pósgraduação em Administração de Empresas da PUC-Rio. Aprovada pela Comissão Examinadora abaixo assinada.
\end{abstract}

Prof. Luis Fernando Hor-Meyll Alvares

Orientador

Departamento de Administração - PUC-Rio

Prof. Luís Alexandre Grubits de Paula Pessôa

Departamento de Administração - PUC-Rio

Profa. Denise Franca Barros

Universidade do Grande Rio

Profa. Mônica Herz

Vice-Decana de Pós-Graduação do CCS

Rio de Janeiro, 3 de julho de 2012 
Todos os direitos reservados. É proibida a reprodução total ou parcial do trabalho sem a autorização da universidade, do autor e da orientadora.

\section{Ricardo do Nascimento Bacellar}

"Graduou-se em Processamento de Dados nas Faculdades Reunidas Nuno Lisboa, atual UniverCidade em 1991, com MBA em Gestão Empresarial (2009) e Mestrado em Administração de Empresas com ênfase em Marketing (2012), ambos na PUC-RJ. Possui 31 anos de experiência profissional no segmento de consultoria atuando nas áreas de marketing, gerência de produtos, e diretoria comercial.”

Ficha Catalográfica

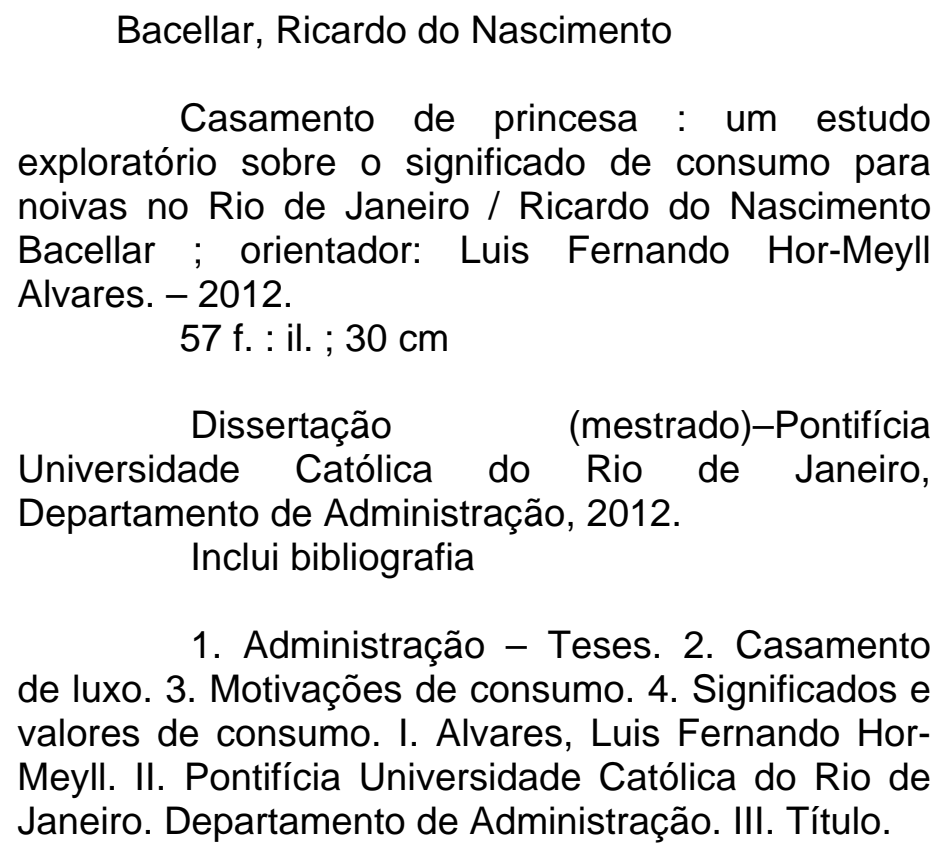

CDD: 658 


\section{Agradecimentos}

A minha esposa Cristina, meus filhos Alexandre e Julia, e meus enteados Diego e Rodrigo. O incentivo, a compreensão e a paciência com que encararam meus momentos de ausência na administração do nosso lar e na posição de Pai / Padrasto foram fundamentais para ajudar a superar os momentos de isolamento necessários ao desenvolvimento deste trabalho.

Aos meus pais, Humberto e Therezinha, por todo exemplo, incentivo e suporte não só durante o Mestrado, mas ao longo de toda minha vida.

À minha empresa, KPMG, pelo patrocínio e suporte à minha decisão de cursar este Mestrado.

Às noivas entrevistadas, que gentilmente participaram dessa pesquisa transformando essa etapa crucial em um momento muito prazeroso e divertido.

Aos cerimonialistas Ana Maria Vieira de Melo, Fernanda Viana e Roberto Cohen, que foram de uma generosidade ímpar ao compartilhar seu enorme conhecimento sobre o tema como valiosa contribuição para a qualidade deste trabalho.

Ao meu orientador Professor Luis Fernando Hor-Meyll pelos ensinamentos, apoio e rigor para que eu alcançasse os meus objetivos.

Ao Professor Luis Alexandre Pessôa pelo suporte adicional de alto valor para o desenvolvimento deste trabalho.

Aos meus professores de todas as disciplinas, por todo conhecimento compartilhado ao longo destes dois anos.

Ao IAG da PUC-Rio, seu corpo diretivo e funcionários, que me proporcionaram todo suporte e infraestrutura necessários para as aulas e desenvolvimento deste trabalho. 


\section{Resumo}

Bacellar, Ricardo do Nascimento; Alvares, Luis Fernando Hor-Meyll. Casamento de Princesa: um estudo exploratório sobre o significado de consumo para noivas no Rio de Janeiro. Rio de Janeiro, 2012. 57p. Dissertação de Mestrado - Departamento de Administração, Pontifícia Universidade Católica do Rio de Janeiro.

O objetivo deste estudo é investigar motivações, crenças e valores simbólicos de serviços e produtos no ritual de um casamento. Conduziu-se um estudo exploratório, baseado em entrevistas em profundidade, com 19 noivas residentes nas Zonas Sul e Norte da Cidade do Rio de Janeiro. Análise de conteúdo das entrevistas revelou o enorme valor simbólico de sua imagem perante os convidados. A crença é de que quanto melhor for a opinião destes sobre o evento, igualmente melhor será a opinião sobre ela própria e sua aceitação no grupo social ao qual pertence. Motivadas a diferenciar sua cerimônia das demais, de transformá-la numa experiência única, vêem suas estratégias racionais de alto controle financeiro, suportadas pelo uso de planilhas de orçamento e inúmeras pesquisas de fornecedor, sucumbir perante a oferta de produtos e serviços inovadores, porém de custo mais elevado. Como resultado, gastos muito acima do esperado no afã de ver seus desejos realizados.

\section{Palavras-chave}

Casamento de luxo; motivações de consumo; significados e valores de consumo 


\section{Abstract}

Bacellar, Ricardo do Nascimento; Alvares, Luis Fernando Hor-Meyll. (Advisor). Princess Wedding: an exploratory study on consumer behavior for brides in Rio de Janeiro. Rio de Janeiro, 2012. 57p. MSc. Dissertation - Departamento de Administração, Pontifícia Universidade Católica do Rio de Janeiro.

The objective of this study is to investigate motivations, beliefs and symbolic values of services and products in the ritual of marriage. An exploratory study was conducted based on interviews with 19 brides living in north and south districts of Rio de Janeiro. Content analysis of the interviews revealed the enormous symbolic value of bride's image to her guests. The belief is that the better the guest's opinion about the event, the best will be their opinion about her and also the acceptance in the social group to which she belongs. Motivated to differentiate her ceremony among the others, to transform it into a unique experience, the bride sees her rational strategies of high financial control, supported by the use of budget worksheets and numerous supplier research, succumbing to the offer of innovative products and services, but at higher cost. As a result, much higher expenditures than expected in eagerness to see her wishes fulfilled.

\section{Keywords}

Lavish wedding; consumption motivations; consumption meanings and values. 


\section{Sumário}

1. Introdução 10

1.1. Contextualização do Problema 10

1.2. Objetivo do Estudo 12

1.3. Relevância 13

2. Casamentos de Princesa 15

3. Revisão da Literatura 20

3.1. Motivações e Necessidades de Consumo 21

3.2. Significados de Consumo 22

3.3. Consumo Hedônico 23

3.4. Pós-Modernismo, a Idade do Símbolo e do Espetáculo 24

3.5. Significados do Consumo na Indústria de Casamentos 26

4. Método $\quad 32$

4.1. Pesquisa Exploratória $\quad 32$

4.2. Seleção da Amostra 33

4.3. Entrevistas em Profundidade 33

4.4. Análise de Conteúdo 36

4.5. Limitações do Método 36

5. Análise dos Dados 37

5.1. Caracterização da Amostra 37

5.2. Resultados 38

5.2.1. Quais os Produtos e Serviços Prioritários? 38

5.2.2. Qual a Importância do Preço? 41

5.2.3. Que Simbolismos são Relevantes 45

5.2.4. Qual a Importância do Carro que Leva a Noiva para a
Cerimônia?

5.2.5. De Quem é a Palavra Final 48

6. Considerações Finais 50

6.1. Conclusões 50

6.2. Recomendações 53

7. Referências Bibliográficas $\quad 54$ 


\section{Lista de figuras}

Figura 1 - Transferência de Significados na Sociedade de Consumo 


\section{Lista de tabelas}

Tabela 1 - Perfil das Entrevistas 